See Article page 90.

\section{Commentary: When the field just}

\section{moves on}

\section{Jacob A. Klapper, MD, FACS}

The relevancy of one's work is often determined by forces outside one's control. In our modern world, the pace at which progress occurs can result in something appearing dated, for lack of a better term, upon its arrival. It is certainly no fault of the individuals pursuing the hypothesis; sometimes the field just moves on. This was my lasting impression when reading Kunitoh and colleagues' randomized study ${ }^{1}$ of adjuvant therapy for stage I resected nonsmall cell lung cancer (NSCLC). Having established in previous trials that tegafur and uracil (UFT) was an effective adjuvant in resected node-negative NSCLC of greater than $2 \mathrm{~cm}$, the authors elected to compare UFT with $\mathrm{S}-1$, a more toxic but potentially more clinically efficacious drug. ${ }^{1}$

When it comes to the central questions surrounding the management of stage I lung cancer in 2020, I must say that adjuvant therapy for resected, node-negative stage I NSCLC is not one of the first that comes to mind. In the West, we have arrived at a seemingly uniform consensus that there are no compelling data to support any additional therapy. Rather, I would posit that the predominant question is not what therapy patients get after surgery but whether they get surgery at all. Stereotactic ablative radiotherapy is now an accepted alternative to surgery, despite a lack of randomized clinical evidence to support its equivalency. In fact, with the failure of the STAR (Surgical Resection In Stage I Non-small Cell Lung Cancer) and ROSEL (Trial of Either Surgery or Stereotactic Radiotherapy for Early Stage (IA) Lung Cancer) studies to accrue patients, surgery alone for these individuals remains the standard of care regardless of the strong assertions that some have made to the contrary. ${ }^{2}$

From the Division of Cardiothoracic Surgery, Duke University Medical Center, Durham, NC.

Disclosures: The author reported no conflicts of interest.

The Journal policy requires editors and reviewers to disclose conflicts of interest and to decline handling or reviewing manuscripts for which they may have a conflict of interest. The editors and reviewers of this article have no conflicts of interest.

Received for publication Sept 8, 2020; revisions received Sept 8, 2020; accepted for publication Sept 24, 2020; available ahead of print Oct 20, 2020.

Address for reprints: Jacob A. Klapper, MD, FACS, Division of Cardiothoracic Surgery, DUMC 3954, Durham, NC 27710 (E-mail: Jacob.klapper@ duke.edu).

JTCVS Open 2020;4:103-4

2666-2736

Copyright (C) 2020 The Authors. Published by Elsevier Inc. on behalf of The American Association for Thoracic Surgery. This is an open access article under the CC BY-NCND license (http://creativecommons.org/licenses/by-nc-nd/4.0/).

https://doi.org/10.1016/j.xjon.2020.09.006

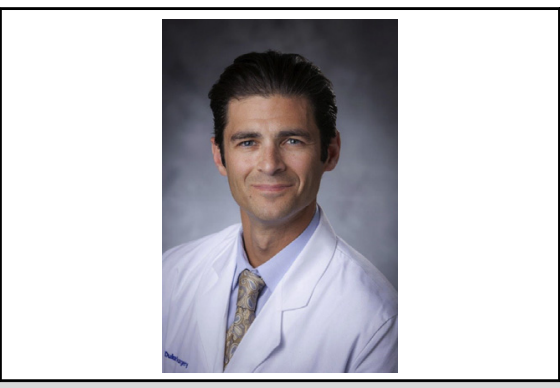

Jacob A. Klapper, MD, FACS

CENTRAL MESSAGE

The current study lacks relevancy

in 2020 , when the use of adju-

vant therapy for stage I lung

cancer seems to be a settled

issue, at least in the Western

world.

Aside from where the discussion has moved since the inception of this trial, the trial itself yielded some concerning results, namely the high percentages of patients in both arms that experienced grade 3 toxicities. For instance, grade 3 toxicities in the UFT arm were $15.9 \%$ and $14.9 \%$ in the S-1 arm. In addition, there were 3 protocol-related deaths in the S-1 group. These toxicities and treatment-related deaths are particularly sobering when you consider that in neither arm was the median overall survival reached at the time of data cut-off. Thus, more than a few patients assumed some significant toxicities being treated for cancers of which they were likely cured, a fact that was confirmed by the authors' acknowledgement that more than a third of patients in both arms died of causes other than cancer.

Twelve years is a long time in oncology, as it is in most fields of medicine these days. At the time this trial began to register patients in 2008, the Journal of Clinical Oncology published the profoundly important LACE (Lung Adjuvant Cisplatin Evaluation) meta-analysis, which confirmed the benefits of adjuvant therapy for resected NSCLC. However, this benefit was reserved to patients with stage II and III lung cancer, with stage IB patients experiencing more mixed results and the chemotherapy being potentially injurious to those with stage IA disease. ${ }^{3}$ The current study, in a sense, reconfirms what we learned from the LACE group more than a decade ago. Perhaps not so much changes after all. 


\section{References}

1. Kunitoh H, Tsuboi M, Wakabayashi M, Okada M, Suzuki K, Watanabe S, et al. A phase III study of adjuvant chemotherapy in patients with completely resected, node-negative non-small cell lung cancer (JCOG 0707). J Thorac Cardiovasc Surg Open. 2020;4:90-102.
2. Chang J, Senan S, Paul M, Mehran RJ, Louie AV, Balter P, et al. Stereotactic ablative radiotherapy versus lobectomy for operable stage I non-small-cell lung cancer: a pooled analysis of two randomised trials. Lancet Oncol. 2015;16:630-7.

3. Pignon J, Tribodet H, Scagliotti G, Douillard JY, Shepherd FA, Stephens RJ, et al. Lung adjuvant cisplatin evaluation: a pooled analysis by the LACE collaborative group. J Clin Oncol. 2008;26:3552-9. 